\title{
Erratum to: Influence of the Sodium Niobate Addition on the Sintering and Properties of Zirconia Ceramics
}

\author{
V. V. Smirnov ${ }^{a} *$, S. V. Smirnov ${ }^{a}$, T. O. Obolkina ${ }^{a}$, M. A. Goldberg ${ }^{a}$, O. S. Antonova ${ }^{a}$, \\ and Corresponding Member of the RAS S. M. Barinov ${ }^{a}$
}

Received July 31, 2019

DOI: $10.1134 / \mathrm{S} 0012500819080093$

On page 143, right column, Section Funding should be read Synthesis of nanodispersed $\mathrm{ZrO}_{2}$ powders, fabrication and study of the microstructure and phase composition of zirconia-based ceramics were supported by the Russian Foundation for Basic Research (project no. 18-29-11053mk). Investigation of the sin- tering of low-temperature ceramics was supported through a grant from the Council for Grants of the President of the Russian Federation for Support of Young Scientists (grant no. MK-5661.2018.8). Studying the porosity and mechanical properties was supported through a scholarship of the President no. SP-3724.2018.4.

The original article can be found on line at https://doi.org/10.1134/S0012500819050033

\footnotetext{
${ }^{a}$ Baikov Institute of Metallurgy and Materials Science, Russian Academy of Sciences, Moscow, 119334 Russia *e-mail: smirnov2007@mail.ru
} 